\title{
Scenarios for resilient drought and water scarcity management in England and Wales
}

\section{Kevin Grecksch}

To cite this article: Kevin Grecksch (2018): Scenarios for resilient drought and water scarcity management in England and Wales, International Journal of River Basin Management, DOI: 10.1080/15715124.2018.1461106

To link to this article: https://doi.org/10.1080/15715124.2018.1461106

Accepted author version posted online: 04 Apr 2018.

Submit your article to this journal $๘$

Q View related articles $₫$

View Crossmark data $₫$ 
Publisher: Taylor \& Francis \& International Association for Hydro-Environment Engineering and Research

Journal: Intl. J. River Basin Management

DOI: $10.1080 / 15715124.2018 .1461106$

Check for updates

\title{
Scenarios for resilient drought and water scarcity management in England
} and Wales

Kevin Grecksch ${ }^{a^{*}}$

${ }^{a}$ University of Oxford, Centre for Socio-Legal Studies, Manor Road Building; Manor Road, Oxford, OX1 3UQ, United Kingdom, email: kevin.grecksch@csls.ox.ac.uk

* corresponding author

\section{Scenarios for resilient drought and water scarcity management in England} and Wales

\begin{abstract}
Current drought and water scarcity management in England and Wales is reactive rather than proactive and the array of instruments and measures focusses primarily on what to do when in a drought but less on how to prevent a drought or to plan ahead for a drought. This paper presents the results of a workshop that was held in late 2016 with stakeholders and researchers from UK drought and water scarcity management - the environment ministry (DEFRA), the Environment Agency, water companies, the economic regulator and water consultancies using the explorative scenario technique. The workshop offered the opportunity for unconstrained blue-sky thinking about drought management options based on the question What can happen? and it is useful in cases where there is fairly good knowledge regarding how the system works at present, but one is interested in exploring the consequences of alternative developments in drought management. The workshop developed four scenarios on
\end{abstract}


the topic of resilient drought and water scarcity management in England \& Wales in 2065: (1) 'Accepting decline', (2) 'Rising to the challenge', (3) 'Enjoying their luck' and (4) 'Passive Acceptance'. The corresponding narratives are presented as are limits of the workshop but also potential uses of the scenarios.

\section{Keywords}

Explorative scenarios, water governance, drought, water scarcity, England, Wales

\section{Acknowledgments}

This work was supported by the UK Natural Environment Research Council [NE/L010364/1].

\section{Introduction}

Despite all stereotypes of England and Wales being countries with steady precipitation, drought and water scarcity are a recurring feature of UK Climate (Marsh et al. 2007). With an increasing population resulting in higher and changing water demands and climate change the situation is expected to worsen in the future (Committee on Climate Change Risk Assessment 2016). Drought and water scarcity potentially have far reaching consequences such as interrupted public water supply, lack of water for irrigation, interrupted industrial supply chains or lack of cooling water for thermal power stations. Effective and sustainable management of water resources therefore is a key element of water governance, of which drought management is only one aspect. Drought management in the UK takes place in a drought governance space (Lange and Cook 2015) characterised by the main actors: private water companies, DEFRA (Department for Environment, Food and Rural Affairs) the Environment Agency (EA), the economic regulator OFWAT (Water Services Regulation 
Authority) and water consultancies. They operate within a legal framework that also prescribes options to manage drought and water scarcity (Environment Agency 2011, 2015).

The recently published UK “25 Year Environment Plan” highlights that: “Our indicators suggest that as many as one-in-five of our surface waters are over-abstracted." (HM Government 2018, p. 68). The report emphasises the need to maintain sustainable supplies of water for future generations and acknowledges that this will require both reducing demand and increasing supply. The UK government sees water companies taking a leading role in fighting unsustainable abstraction and also wants to increase water efficiency and reduce leakage (ibid., p. 70). However, more concrete measures are not mentioned in the plan. Robins et al. (2017, p. 42) state: “The UK's water challenges extend beyond those related to environmental processes and impacts on infrastructure to the supply of water to both domestic and business markets, and to the treatment of wastewater." Currently, the UK is entangled in a network of international and domestic regulations. Several European Union directives, most prominently the EU Water Framework Directive and the EU Floods Directive, shape UK water governance but there is also a complex interplay domestically with regulatory bodies in all four nations of the United Kingdom. The UK's decision to exit the European Union following an advisory referendum in 2016 will prove another challenge for water governance in the UK. Whether existing regulations will be kept or whether the UK will see a whole new system or policy of managing water or the environment in general is yet unknown. Even the aforementioned UK “25 Year Environment Plan” only hints at this in a very general statement: "Leaving the EU presents a unique opportunity to set in motion the behavioural and institutional changes necessary to build sustainable, enduring growth as well as an improvement in our wellbeing.” (HM Government 2018, p. 11)

Thus, given current and future challenges such as policy changes, climate change, population growth and changing demand patterns, it is also necessary to take a future facing 
perspective and discuss qualitatively the potential effectiveness of and constraints upon these options with stakeholders. A few publications have recently discussed future-oriented, outward-looking aspects of water governance with a focus on the UK and with a focus on drought management. Robins et al. (2017) highlight the complex institutional and governance arrangements and policy settings across the United Kingdom and conclude with ten ways to improve and reinvigorate water policy in the UK. One of the ten recommendations, and relevant for the focus of this research, is "to step back and take a systematic, long-term view of water resources management“ (ibid.). Sayers et al. (2017) more specifically developed eight golden rules for strategic drought management. Among them are to "set multiple goals and objectives that promote positive long-term outcomes for society”, "encourage stakeholders from a variety of different sectors and realms to participate or "assess whole system behaviour and associated risks and uncertainties over the short and long term” (ibid.).

But how exactly do we approach long-term views or assess risks and uncertainties and how do we promote positive long-term outcomes for society? The research presented in this paper contributes to tackle the question about future drought and water scarcity management in England and Wales by developing four explorative scenarios based on the results of an explorative scenario workshop held at the University of Oxford' Centre for Socio-Legal Studies on 15 September 2016.

Building or developing scenarios for the UK water sector is not a novel idea, however, the approaches and methods differ or are unclear. Water UK, the membership organisation representing the UK's major water and wastewater service providers, produced a long term planning framework for the UK water resources ranging from 2015-2065 (Water UK 2016). The report provides an assessment of drought resilience of existing and future national water resource systems, based on climate change perturbations of the historic climate and under alternative more severe drought scenarios, which have been generated through 
stochastically based modelling. Based on this framework the report uses 36 scenarios or representative futures trying to account for the uncertainties in future supplies and demands (ibid.). The usefulness of the report is limited to water companies and regulatory bodies. Recommendations for customers and stakeholders are limited to one page within a twohundred pages report.

The consultancy Atkins has published the "Future Proofing the UK Water Sector" report which examines four possible future scenarios to determine how drivers such as climate change and population growth could affect the UK's water sector to 2050 (Atkins 2013). The report develops and describes four scenarios - The Graphene Era, The Wood Economy, The Steel Squeeze, The Concrete Jungle - "constructed around two important and highly uncertain drivers of change for the water industry - the cost and availability of energy, and the value customers place on natural resources" (Atkins n.d.). However, this information is taken from their website and only indicates the methodology, explorative scenarios. The report itself does not describe the methodology nor does it explain who was involved in the development of the scenarios.

Most recently, the Enyironment Agency developed and explored four plausible future scenarios - uncontrollable demand, innovation, sustainable behaviour, local resilience - and a reference scenario for the water environment for England and Wales through to 2050 (Centre for Environmental Risks and Futures (CERF), Garnett, et al. 2017). These are existing socioeconomic scenarios, previously developed by the EA and DEFRA, yet in this case they were elaborated for application to river basin management. According to the report, the intention was to "use the scenarios to explore implications for managing water and the water environment in terms of pressures nationally and in different catchment types (for example, phosphorus concentrations in rivers) and to different sectors including the general public, manufacturing industries, leisure industries, utility companies (water and energy), and 
farming and fisheries.” (ibid.). The method is well described as "participatory approach including workshops, telephone interviews and dedicated desk research” in a separate report (Centre for Environmental Risks and Futures (CERF), Delgado, et al. 2017).

In summary, scenarios for the UK water sector exist but with differing focus, quality and the years they were developed. Scenarios are therefore a common technique or method in UK water resources management. A parapgraph in the next section will also briefly comment on the scenarios water companies use in their water resources management planning. The scenarios presented here focus on drought and water scarcity in England and Wales, an underrated issue in the UK's public debate about water resources. Furthermore, the scenarios developed in this research are unique in the sense that they are exploratory, i.e. they are not built on pre-existing scenarios, they tried to include a wide range of stakeholders and they allowed for blue-sky thinking. The scenarios could be a useful tool in policy formulation and managing complex environmental problems such as drought and water scarcity as will be discussed later. In the following, the paper presents an overview of the research design, it summarises the results and discusses potential uses of the outcomes.

\section{Method}

\section{Explorative Scenario Workshop}

An explorative scenario workshop offers the opportunity for unconstrained blue-sky thinking, in this case about drought and water scarcity management, based on the question what can happen. It is a useful approach where there is fairly good knowledge regarding how the system works at present, but one is interested in exploring the consequences of alternative developments of in this case drought and water scarcity management.

Scenario building is an established method for strategic planning (Mietzner and Reger 2004). The IPCC highlights scenario planning as an adaptive approach to water management 
to reduce uncertainty (Jiménez Cisneros et al. 2014, p. 254). Flynn et al. (2018) assess that scenario planning approaches are increasingly used in climate change research to identify future vulnerabilities and examine adaption options. Durance and Godet provide a recent introduction into the area and its origins (Durance and Godet 2010) and they also provide a definition: "A scenario is not a future reality but rather a means to represent it with the aim of clarifying present action in light of possible and desirable futures.” (ibid. 2010,p, 1488) Kosow \& Gaßner (2008) define scenarios similarly but also point out the limits: “A scenario can be defined as a description of a possible future situation, including the path of development leading to that situation. Scenarios are not intended to represent a full description of the future, but rather to highlight central elements of a possible future and to draw attention to the key factors that will drive future developments.” (2008, p. 1) Generally speaking, there are three different types of scenarios and scenario building methods that all try to think about the future in a structured way - prognostic, explorative and normative (Börjeson et al. 2006). In this case, an explorative scenario building workshop was chosen. The aim is to develop scenarios for possible trajectories and thinkable future situation. At the centre is the question "What can happen?" As opposed to prognostic scenario building exercises that try to map the future in a narrow corridor ("What will happen?"), in this case the future "space" is deliberately wide to allow for eliciting different thinkable futures. Normative specifications ("What should happen?”) do not play a role or if at all only a minor role (Börjeson et al. 2006). In order to open up the currently constrained set of drought and water scarcity management options, thus being as explorative as possible, they were not suitable.

A precondition for the development of explorative scenarios is, as mentioned above, a fairly good knowledge of the subject - drought and water scarcity management. All participants fulfilled this condition by either being engaged in research on drought and water 
scarcity or by working on drought and water scarcity issues as a consultant, regulator or for a water company (see next section). In addition, the workshop was conducted in a reduced timeframe. While usually two to three days are allocated to run a scenario workshop, this workshop was completed within one day. One of the main reasons was to encourage as much participants as possible but also taking stakeholder's time constraints into account. This however implicated some methodological adjustments, which will be described later. The central steps of the workshop were as follows (i) definition of problem frame, (ii) identification and grouping of influencing factors (“drivers”) for future development, (iii) selection of relevant drivers for scenario development, (iv) scenario deyelopment and (v) scenario description.

Finally, Robinson (1988) points out that a set of paradoxes underlies future studies and some of these issues will be addressed in the Discussion section. First, the future is unknowable since it has not happened. Second, the study of future really is the study of data from the past and present. Third, what will occur in the future is determined by choice and behaviour in the present. Fourth, futures analysis is inherently value-laden. And fifth, as the importance of future analysis increases due to the growing scale, complexity and lead times of major projects, its difficulty also increases, for the same reasons. (ibid.) Yet, "People need the future; in other words, they need hope. This collective need is best expressed if channeled through some form of method.” (Durance and Godet 2010, p. 1491)

In order to avoid confusion it is necessary to mention that UK water companies undertake scenario exercises on a regular basis but it should become clear from the following description in how far this differentiates from the above described explorative scenarios building method applied in this research. According to the UK Environment Agency's Drought Planning Guideline (2011): "Water companies should use scenario assessment to test 
how robust its drought triggers are and to demonstrate how drought management actions would be implemented given a range of drought conditions and elevated demands anticipated during a drought. A company should describe its approach to scenario testing, set out its assumptions and demonstrate how this has been used to help develop drought triggers.” The guideline goes on to prescribe different drought durations that should be assessed (ibid). A similar approach is demanded for the Water Resources Management Plan, another statutory requirement for UK water companies. In its guideline the water companies are required to test their systems by looking at high demands and low supplies based on a dry year annual average for demand and a design drought for supply (Environment Agency and Natural Resources Wales 2016).

\section{Workshop Participants}

This research is nested within the UK-based MaRIUS (Managing the Risks, Impacts and Uncertainties of Droughts and Water Scarcity) project, which influenced the selection of stakeholders. One part of the participants was recruited from the MaRIUS project itself and included six researchers from different project workstreams and included disciplines such as agricultural economics, hydrological modelling or social scientists. The other parts of the participant group were recruited from the project's stakeholder advisory group and included representatives from regulatory bodies (4), water companies (1), consultancies (2) and the energy sector (1). Thus, 14 participants attended the workshop (table S1). Other stakeholders for example from NGOs were invited but either declined, did not respond or were unable to attend the workshop due to time constraints.

\section{Results}


The workshop was organised as a one day workshop and was designed with as little classroom style lecturing as possible but instead putting the emphasis on participatory elements and discussions.

\section{Definition of problem frame}

The first step defined the problem frame according to space, time and topic (Table 1). The spatial dimension, "England \& Wales”, was easily agreed upon by the participants, yet the temporal and topical dimension sparked some discussion. The decision to opt for 2065 as temporal dimension was based on UK water industry decision-making procedures around future planning and risk management. Some participants suggested two dates, for example 2040 and 2065. The first date would be about what needs to be put in place and the second would be about testing the legacy of what has been done against what has been expected over the longer time frame. However, having two dates as temporal dimension would have harmed the methodological feasibility of the workshop and was subsequently discarded. With regard to the topical dimension, the original proposition of "Resilient Drought Management" was amended to "Resilient Drought and Water Scarcity Management". Water scarcity management was seen as broader and more complex than just focussing on responses to drought events, especially with regard to the long term perspective of the workshop. The discussion also proved that there is no consensus over the definition of drought. LloydHughes (2013) describes drought as a "deficit of water relative to normal conditions" and the UK Environment Agency (2015) differentiates between an environmental drought, an agricultural drought and a water supply drought. However, it is important to emphasise that drought is not just a natural event of limited duration, but also a socially constructed event as it can result of social factors such as agriculture, housing and transport policies that have contributed to changing rainfall patterns (Lange and Cook 2015). Droughts are process 
specific, local in space, local in time of the year and predicated on the existence of the climatological norm of a process-specific reservoir term (Lloyd-Hughes 2013). Water scarcity is defined as the result of long-term unsustainable use of water resources, which water managers can influence (Van Loon and Van Lanen 2013). It is hence human induced and subject to the socio-political and economic context (Walker 2014). Thus, the problem frame was also deliberately chosen as wide as possible to reflect future exploration, thereby including as many potential influencing factors as possible.

[Table 1 near here]

\section{Identification of drivers and grouping}

The next step was to identify key influencing factors or drivers for resilient drought and water scarcity management. Participants were handed out five index cards each and were asked to write down, based on their knowledge and background, what they thought are the most important influencing factors or drivers with reference to the problem frame. Subsequently, each card was briefly discussed among all participants and thematically grouped. Ambiguous or to generic drivers were further differentiated or assigned to more than one thematic group if the participants agreed. For example "Population and climate change" can be found in the group "Weather/Climate" (figure S1) as well as under "Economic Development""Population growth" (figure S3). The following group headings emerged from the exercise:

- Policy

- Weather/Climate

- Economic Development

- Behaviour

- Environmental Needs 
- Intervention

Figures 1 shows one group "Policy" and already includes the next step of the workshop as well. The corresponding results for the other groups can be found in the supplementary material (figures S1 to S5).

[Figure 1 near here]

\section{Selection of relevant drivers}

Four breakout groups were formed in the next step and each group was assigned one or two thematic groups of drivers. At this stage of the workshop, the aim was to identify those drivers that are of a high importance for resilient drought and water scarcity management in England and Wales in 2065 and at the same time are characterised by high uncertainty with regard to them becoming effective or actually happening. The focus on important and uncertain drivers, the critical uncertainties, satisfies the objective of developing explorative scenarios: generating a wide spectrum of thinkable and potentially highly relevant futures.

The influencing factors were placed on a two-dimensional coordination system showing importance on the $y$-axis and uncertainty on the $\mathrm{x}$-axis. At this stage, participants were also free to add further influencing factors or differentiate existing drivers further. The total number of drivers was 59 (Table S2). Each breakout group presented its results to the audience. Based on that all participants decided upon which factors to take to the next stage of the workshop. This meant selecting the top right quadrant in each case as this reflects the factors that are potentially of high importance but also highly uncertain. Precisely because they are of high importance and high uncertainty they are interesting for future scenarios. These critical uncertainties should be taken forward to the next stage of scenario development 
because they define the future success of drought and water scarcity management. We do not know whether the impact will be negative or positive but it will have an impact. For example, extreme weather events may occur more frequently or not, yet they will have a strong impact on how water companies manage water resources.

In contrast, factors that are of high importance but only have a low uncertainty are not of the same interest level. For example, demographic trends such as population growth in the UK are well researched and the continuation of this development is rather certain. It will nonetheless have an impact on water resources management. Figures 1 and 2 show two examples. Table 2 lists all 36 drivers from the top right quadrant in each thematic group.

[Table 2 near here]

The 36 drivers identified as highly important and highly uncertain were further weighted among each other. The core question was, which of these drivers are the most important for resilient drought and water scarcity management in England and Wales in 2065? Therefore, each participant had four votes, whereby more than one vote could be assigned to a driver. Voting was made using sticky dots, which participants put on the driver(s) of their choice. Table 3 presents the "ranking" of the drivers, reduced to those that received at least two points assuming that it at least hypothetically reflects the interest of two people. A full list is available in the supplementary material (Table S3). This step is a methodological simplification of the scenario building method. Usually this step is followed by a crossimpact analysis, where all highly uncertain and highly important drivers would be juxtaposed and their reciprocal influence assessed (cf. Kosow and Gaßner 2008, p. 57). Due to time constraints, this step was not carried out during this workshop. Instead, the participants engaged in an open and fruitful discussion about which drivers could be used to develop 
scenarios. This methodological simplification puts the focus again on the workshop participants and builds on their expertise. As mentioned before, the whole scenario workshop is participant driven, beginning by writing down influencing factors and ranging to placing factors on the importance-uncertainty grid. Thus, it is argued that by leaving the selection of the most critical influencing factors and drivers to the participants and let them rank drivers and factors using a simple voting system, is consistent with the method. In addition, this methodological simplification has been applied before successfully (Grecksch et al. 2015). It should be noted though, and this will be further discussed in a reflection of the method, that all participants are biased by the present when making judgements about the future. Another problem could be that participants "follow the herd", i.e. they place sticky dots were there are already other sticky dots. This could be overcome in future scenario building workshops of this kind by carrying out a secret vote.

[Table 3 near here]

\section{Scenario Development}

To kick off the discussion, the drivers with the highest number of points awarded were juxtaposed in different combinations. Therefore, they were placed on a two-dimensional matrix, where the axes represent the different developments of the driver. The combination of 'Extreme weather events' and 'Society's expectations' (Figure 2) was selected by the participants as the most feasible, i.e. they evoked the clearest idea about the future of drought and water scarcity management in England and Wales. Another combination, "sharing water" and "cost of failure" was briefly discussed but could not elicit comparable concrete and consistent ideas about the future of drought and water scarcity management. Kosow and Gaßner (2008, p. 60) point out that "all systematic-formalized scenario techniques are alike 
in that they contain subjective and intuitive aspects, e.g. both in their definition of the main characteristics of key factors and in the selection of scenarios which in actual practice have a greater impact than may at first appear to be the case upon reading their theoretical description.” However, this technique - creating two times two scenarios - reduces complexity and it allows that all possible values of key drivers can be combined with all other key drivers in order to formulate the basis for each scenario (see also next section) (ibid. p. $62)$.

[Figure 2 near here]

Each matrix quadrant generated a scenario and the following scenario titles were developed by the participants:

- Scenario 1: “Accepting Decline”

- Scenario 2: "Rising to the challenge"

- Scenario 3: "Enjoying their luck"

- Scenario 4: "Passive acceptance"

\section{Scenario Description}

The last step, the scenario description, could only be touched upon during the workshop and was further elaborated in the aftermath of the workshop by the author and workshop facilitator in the form of narratives. The scenario narratives were sent to all workshop participants for comments before being finalised. Hence, the rather rough four scenario sketches described in the previous section were elaborated. This also included the list of highly important and highly uncertain drivers. Each narrative orientates itself along the list of key critical drivers. Yet, the focus of this step was not their possible exploration or different development. Instead, the focus was on developing four self-consistent and per se plausible 
scenarios that are different and interesting enough to act as generators of further processes. Thus, in order to be consistent, each scenario is, apart from a narrative, described using each critical driver and how each critical driver would develop under each of the four scenarios. Table 4 is another tool helping to create consistency because it is a very good reference point at this stage. Plausibility is reached by first of all referring to real places and regions and second, by referring to existing and known water resources management challenges. The clearest indication can be found for instance in the first scenario where it refers to London's desalination plant. All scenarios are also under the assumption that the UK still is a parliamentary democracy in 2065. These measures add credibility, believability, thus plausibility. The narrative, quasi-literary approach also helps to achieve a high degree of concreteness, detail and realism. It is also effective for communication purposes. (Kosow and Gaßner 2008) In the following a narrative for each scenario is presented. A full account of how each highly important and highly uncertain driver develops under each scenario can be found in the supplementary material.

\section{Scenario 1: "Accepting Decline"}

In the year 2065 England and Wales are more frequently hit by extreme weather events. River flooding, coastal storm surges and frequent drought events have become a common phenomenon. At the same time society's expectations towards water are very low. People expect public water supply to deliver water to their households without interruption and regardless of any environmental implications.

Droughts and other extreme weather events frequently occur in England and Wales as a result of climatic changes. The regions of England and Wales are affected differently though. Worst affected is the Southeast, which has seen a growing water demand due to a rising population. A growing wine, fruit and vegetable business in the region has put further 
stress on the available water resources. Londoners frequently queue for water after extreme events as the city is low on drinking water availability. Plans for new reservoirs and an interbasin water transfer scheme had been dropped due to high costs and the unwillingness of both responsible water companies to reach an agreement on sharing water. The desalination plant at Beckton, once built as a backup facility, is now operating 365 days a year to supply the capital with water. The energy costs outweigh the costs for repairing leakages as public support for water supply disruption to carry out the necessary leakage repairs is low.

In the north, the people of West Cumbria are completely cut off public water supply after plans to build a pipeline from an adjacent water resource zone had to be dropped. Public pressure from customers to prioritise them over West Cumbrian customers led to this decision. The people of West Cumbria now rely on the few remaining local sources and tankering by lorries after extreme weather events.

Society's expectations towards water are very low. People see water as a commodity they pay for and hence one that has to be delivered to their households. This results from a general decline in environmental standards and low demands for environmental quality. The increased frequency of extreme events and its consequences have shifted public attention towards restoring vital infrastructure and creating jobs. Environmental aspects only play a minor role in these policies. Water companies are struggling between providing customers with water they paid for and sourcing that water are unwilling to share any water with other companies. This cannot be justified against their customer’s expectations.

Society lacks a general understanding and interest on the interconnectedness of extreme weather events and integrated water resources management. Integrating drought and flood policies, or mitigating and adapting to climate change rank low on the political agenda. People accept a decline in extreme weather event protection as the rising costs of protection and disaster reduction can no longer be justified. 


\section{Scenario 2: "Rising to the Challenge"}

England and Wales are frequently hit by extreme weather events among them droughts. Yet, society's expectations towards water are very high. People are aware of increased extreme weather events and they are well prepared. This reduces the costs of extreme weather events. People actively engage in environmental protection and are water aware. They make use of the latest water saving technology at home and at their workplaces.

Droughts and other extreme weather events occur more frequently in England and Wales and have different consequences in the different regions. However, a national interbasin transfer scheme and cooperation among water companies ensure a continuous water supply across the island. Floods are also among the increased extreme weather events but instead of dredging rivers, the policy is to store water where possible and make it available when needed. The government has anticipated that environmental challenges such as climate change are interlinked with other societal challenges such as migration, population growth and economic prosperity. All policies have to undergo a climate change test. This ensures for example that floodplains are not available as land for housing or business use. New legislation also introduced the rule that whenever a property has been flooded it cannot be rebuilt at the same spot. However, compensation is paid to the property owner, yet the compensation costs outweigh the cost of restoring the property after each extreme weather event. A side effect of this policy is the increasing availability of land for floodplains, which also helps to hold water back.

The society is very water aware and is able to rise to the challenge of increasing extreme weather events. The link between water, energy and food is at the core of school and university curricula. New housing estates automatically require the installation of a grey water reuse scheme to save water. Businesses in industrial estates actively engage in 
collaboration with their business neighbours to assess the potential of saving water through grey water reuse schemes. Increasing extreme weather events have made people aware about the fragility of nature and the precious resource water. Reducing water consumption and mitigating the consequences of future extreme weather events is therefore high on the agenda. A whole new business sector has developed around making more water available either through technological measures or education.

\section{Scenario 3: "Enjoying their luck"}

The number of extreme weather events in England and Wales has decreased. Despite this trend, society's expectations towards water are very high. People are well prepared for drought periods and proactively engage in drought prevention measures. They save water and they are well prepared for the rare extreme weather events.

Droughts and other extreme weather events occur less frequently in England and Wales. In case of an extreme weather event water companies, authorities and society are well prepared. For example, those regions that could be affected by drought the most are connected to other water resource zones to quickly transfer water when needed. In addition, floodplains have been restored where it was possible, yet especially in areas with a large share of environmentally active people. They demanded measures although the frequency of extreme weather events has decreased. Overall, society is enjoying its luck that government policy is environmentally friendly and benefits from less frequent extreme weather events.

People are water aware and acknowledge the water-energy-food-nexus. Both are an essential part of education although due to the reduced number of extreme weather events environmental protection goals are frequently put into question. Water companies have to actively promote water saving devices and metering although people quickly enjoy the benefits of both. 


\section{Scenario 4: "Passive Acceptance”}

The number of extreme weather events has decreased in England \& Wales. However, this led to a decrease in public interest in environmental issues and environmental awareness. Water companies have to deal less with emergency measures and focus on meeting supply and demand. As long as they meet both, customers are satisfied and show no further interest in saving water.

Droughts hit England and Wales only occasionally and affect only certain regions. Although the consequences after each event are devastating for the affected regions, planning for future drought events does not change. The low number of extreme drought events does not justify any measures beyond restoring the supply and demand balance. Government priorities have shifted away from environmental issues to economic growth. In addition, society lacks a general understanding and interest on the interconnectedness of extreme weather events and integrated water resources management. Integrating drought and flood policies, or mitigating and adapting to climate change rank low on the political agenda.

People are passively accepting the fact that extreme weather events rarely occur, are being dealt with and hence they do not demand any improved water supply infrastructure, leakage repair or water saving education.

\section{Discussion}

This one-day workshop aimed at generating explorative scenarios for resilient drought and water scarcity management in England and Wales by 2065. The key critical drivers, which were developed and assessed by the workshop participants cover aspects such as changing attitudes towards water use, extreme weather events, integrating flood and drought policy, the willingness to share water or the state of the environment. These drivers have been mapped in 
the framework of four scenarios and Table 4 summarises the development of each driver under each scenario again.

[Table 4 near here]

The question remains in how far these scenarios are daring enough to look beyond one's own nose? Some participants struggled with the idea of explorative thinking in the sense that normative issues of drought and water scarcity frequently emerged during the discussions. For example, the breakout group "Weather/Climate" added arrows to its coordination system to point out that some aspects, such as science, regional differences or changes in water quality were difficult to pin down to a certain point on the coordination system (figure S1). A second discussion arose around the issue of "Funding for infrastructure". While the "Policy" breakout group placed it as relative highly important and highly uncertain (figure 1), others argued that the funding as such will not be uncertain but it is rather the source of funding that is uncertain. Furthermore, it was discussed in this regard that it is the intergenerational dimension of funding that creates uncertainty. One participant however clearly maintained the position that the cost of funding is of high impact but of low uncertainty (Grecksch 2017). A clear limit of the workshop was the lack of participants from (environmental) NGOs, who as described earlier were not able to attend or did not respond to requests. However, the representative from the energy sector proved to be a good participant in the sense that he brought novel insights and different perspectives into the discussion as some of the participants acknowledged. Nonetheless, key actors from the UK drought governance space (Lange and Cook 2015) attended the workshop. For future workshops of this kind it would also be useful to include stakeholders from neighbouring policy sectors to emphasise the integrated nature of water resources management (Krueger et al. 2016, Garrote 2017). 
Participatory scenario development is a dialogue between individuals that helps to integrate multiple perspectives to collectively imagine and explore different plausible futures (Wilkinson and Eidinow 2008). With regard to the usefulness for the MaRIUS project, but also beyond, three possible uses are foreseeable. First of all, with regard to decision-making the scenarios present four alternative developments for drought and water scarcity management in England and Wales by 2065. This could be useful for water companies and regulatory bodies when developing strategies for future water resources management. Scenarios can therefore promote a shared sense of responsibility and mutual learning. They can be used to test the strength of existing plans, policies or investments on help develop new ones, contributing to informed decisions (Faling et al. 2017). Thus the scenarios developed in this research can be seen as an addition to the debate about drought and water scarcity management in England and Wales or even water resources management in general. The identified two most critical drivers - extremes weather events and society's attitude towards water - are issues that relate to water governance in general and not just drought and water scarcity management. Water companies and regulatory bodies could add the scenarios to their portfolio of planning tools and data. However, compatibility is an issue. Discussions within the project team have shown that a lot of them struggled with the purpose and the idea of non-normative scenarios. The discussion was led along the divide between social and physical sciences and especially for the latter, the idea of blue-sky thinking without a normative goal proved to be not feasible for many of them.

Second, the results of the workshop could be the basis for a further exercise - for example backcasting (Robinson 1988, van der Voorn et al. 2012, Grecksch et al. 2015) The idea behind backcasting would be to select one of the scenarios as the most desirable one to reach in the future. A backcasting workshop then tries to identify options to connect the future to the present and establishes what actions must be taken to attain a certain goal, i.e. scenario. 
Ideally, this results in a programme of measures that would be implemented at certain times along the time frame, in this case 2065. A third possible use of the scenarios would be to use them in the project's drought modelling and to test how each scenario would influence the different parameters in a model and to see the impacts under the various scenarios. However, the latter two possible uses of the scenarios were not further pursued in the project also due to time and resource restrictions. Nonetheless, the scenarios are one among the many and wide ranging outcomes of the project.

Carrying out the workshop in one day proved to be both useful and challenging. As mentioned above a scenario planning workshop can take up to three days including the development of scenario storylines. However, in reality, this is hardly a feasible timeframe especially for participants from the private sector but also public sector who need to justify to their superiors, if they have any, why they need to take part in a multi-day workshop. One way to overcome this would be to embed scenario planning workshops in actual policy formulating process, i.e. the results will inform decision-making. A one day workshop also puts pressure on the facilitator. The workshop at least needs to reach the stage of scenario development. The actual writing of the scenarios can be done, as in this case, by the faciltiator, or if possible, by small teams made up of workshop participants. Both cases require strict timelines in order to finalise the process. While the experience of writing in a small team during the actual workshop can be rewarding and joyful, formulating the scenarios at one's office or home desk is also legitimate. Besides putting pressure on the facilitator, a one day workshop also puts pressure on the participants. The experiences made by the author during several scenario planning workshops in the past was that participants can get enthusiastic and want to reach the goal of developing scenarios. This is further supported by the structure of the method, i.e. incrementally reducing a large number of factors and drivers to small number of critical drivers adds "suspense" to the exercise. Thus, so far 
reducing scenario planning to a one day workshop has proved useful because it increases the likeliness of stakeholders to participate and it also ensures a useful result.

\section{Conclusion}

An explorative scenario workshop tries to engage stakeholders into blue-sky thinking and to develop scenarios that open up the discussion about possible future developments. The research presented in this paper highlighted the results of such a scenario workshop in the context of drought and water scarcity management in England and Wales. The outcomes proved this to be a successful and interesting exercise for all participants. Although the majority of participants knew each other in a professional capacity before the workshop, exchanging ideas and sharing thoughts provided novel insights.

However, it became also obvious during the workshop that making claims about future developments are even more difficult when they do not relate to technological options but relate to complex societal or political conditions a few decades ahead. Developments that strongly differ from current situations, breaks, are less seldom conceived. Instead, current "trends" are continued because they are in a way "inspiring”. In other words, our thinking about the future is influenced by current events and developments. The futurologist De Jouvenel pointed out that our view of reality is often blurred by: “(1) means of observations, or even more rudimentary, our sources of information: (2) means of measurement or quantification, for example, the GNP per capita, which tends to favour whatever is expensive over that which is not, and which occasionally overestimates what could be seen as accessory while underestimating the essential; (3) weight of the theories that we use to explain phenomena; theories that often lag behind reality.” (De Jouvenel 2000, p. 39).

Hence, the workshop results can be seen as contribution to the debate about future water governance in England and Wales, which of course does not only include drought and 
water scarcity management, but all aspects of water resources management. In this regard, the selection of "society's expectations/water use culture" as one of the key drivers is also a useful hint towards a more integrated approach to water governance in England and Wales.

\section{References}

Atkins, n.d. Future proofing the UK water sector [online]. Available from: http://www.atkinsglobal.co.uk/en-GB/group/sectors-and-services/sectors/water/futureproofing-the-uk-water-sector [Accessed 2 Feb 2018].

Atkins, 2013. Future Proofing the UK Water Sector. Positioning the UK water industry for long term success. Epsom.

Börjeson, L., Höjer, M., Dreborg, K.-H., Ekvall, T., and Finnveden, G., 2006. Scenario types and techniques. Towards a user's guide. Futures, 38, 723-739.

Centre for Environmental Risks and Futures (CERF), Delgado, J., Henriques, C., Garnett, K., Lickorish, F., Holman, I.P., Forrow, D., Rathe, A., Shaw, H., Prpich, G., Weeks, J., and Pollard, S., 2017. Delivering sustainable river basin management: plausible future scenarios for the water environment to 2030 and 2050. Report B: Full Scenarios. Bristol: Environment Agency.

Centre for Environmental Risks and Futures (CERF), Garnett, K., Henriques, C., Delgado, J., Lickorish, F., Forrow, D., Rathe, A., Shaw, H., Prpich, G., Weeks, J., and Pollard, S., 2017. Delivering sustainable river basin management: plausible future scenarios for the water environment to 2030 and 2050. Report A: Overview. Bristol: Environment Agency.

Committee on Climate Change Risk Assessment, 2016. UK Climate Change Risk Assessment 2017. Synthesis Report: priorities for the next five years. London.

De Jouvenel, H., 2000. A Brief Methodological Guide to Scenario Building. Technological Forecasting and Social Change, 65, 37-48.

Durance, P. and Godet, M., 2010. Scenario building: Uses and abuses. Technological Forecasting and Social Change, 77 (9), 1488-1492.

Environment Agency, 2011. Water company drought plan guideline. Bristol.

Environment Agency, 2015. Drought Response: our framework for England. Bristol.

Environment Agency and Natural Resources Wales, 2016. Final Water Resources Planning Guideline, May 2016. Bristol: Environment Agency.

Faling, M., Garard, J., Schouten, G., Schulz, K., Veeger, M., Vervoort, J., and Rutting, L., 2017. Innovative Participatory Research Methods in Earth System Governance. Annual Review of Social Partnerships, (12), 76-80.

Flynn, M., Ford, J.D., Pearce, T., and Harper, S.L., 2018. Participatory scenario planning and climate change impacts, adaptation and vulnerability research in the Arctic. Environmental Science \& Policy, 79 (Supplement C), 45-53.

Garrote, L., 2017. Managing Water Resources to Adapt to Climate Change: Facing Uncertainty and Scarcity in a Changing Context. Water Resources Management, 31 (10), 2951-2963.

Grecksch, K., 2017. Resilient Drought and Water Scarcity Management in England and Wales in 2065. A scenario workshop report. Oxford: Centre for Socio-Legal Studies, University of Oxford. 
Grecksch, K., Garrelts, H., Winges, M., Grothmann, T., Flitner, M., and Bernd, S., 2015. Regionale Governance zur Anpassung an den Klimawandel. In: B. Siebenhüner and A. v. Gleich, eds. Regionale Klimaanpassung im Küstenraum. Marburg: Metropolis.

HM Government, 2018. A Green Future: Our 25 Year Plan to Improve the Environment. London: HM Government.

Jiménez Cisneros, B.E., Oki, T., Arnell, N.W., Benito, G., Cogley, J.G., Döll, P., Jiang, T., and Mwakalila, S.S., 2014. Freshwater resources. In: C.B. Field, V.R. Barros, D.J. Dokken, K.J. Mach, M.D. Mastrandrea, T.E. Bilir, M. Chatterjee, K.L. Ebi, Y.O. Estrada, R.C. Genova, B. Girma, E.S. Kissel, A.N. Levy, S. MacCracken, P.R. Mastrandrea, and L.L. White, eds. Climate Change 2014: Impacts, Adaptation, and Vulnerability. Part A: Global and Sectoral Aspects. Contribution of Working Group II to the Fifth Assessment Report of the Intergovernmental Panel of Climate Change. Cambridge, United Kingdom and New York, NY, USA: Cambridge University Press, 229-269.

Kosow, H. and Gaßner, R., 2008. Methods of Future and Scenario Analysis: Overview, Assessment, and Selection Criteria. Bonn: DIE - Deutsches Institut für Entwicklungspolitik.

Krueger, T., Maynard, C., Carr, G., Bruns, A., Mueller, E.N., and Lane, S., 2016. A transdisciplinary account of water research. Wiley Interdisciplinary Reviews: Water, 3 (3), 369-389.

Lange, B. and Cook, C., 2015. Mapping a Developing Governance Space: Managing Drought in the UK. Current Legal Problems, 1-38.

Lloyd-Hughes, B., 2013. The impracticality of a universal drought definition. Theoretical and Applied Climatology, 117 (3), 607-611.

Marsh, T., Cole, G., and Wilby, R., 2007. Major droughts in England and Wales, 1800-2006. Weather, 62 (4), 87-93.

Mietzner, D. and Reger, G., 2004. Scenario Approaches - History, Differences, Advantages and Disadvantages. In: Proceedings of the EU-US Scientific Seminar: New Technology Foresight, Forecasting \& Assessment Methods. Sevilla.

Robins, L., Burt, T.P., Bracken, L.J., Boardman, J., and Thompson, D.B.A., 2017. Making water policy work in the United Kingdom: A case study of practical approaches to strengthening complex, multi-tiered systems of water governance. Environmental Science \& Policy, 71, 41-55.

Robinson, J.B., 1988. Unlearning and backcasting: Rethinking some of the questions we ask about the future. Technological Forecasting and Social Change, 33 (4), 325-338.

Sayers, P.B., Yuanyuan, L., Moncrieff, C., Jianqiang, L., Tickner, D., Gang, L., and Speed, R., 2017. Strategic drought risk management: eight 'golden rules' to guide a sound approach. International Journal of River Basin Management, 15 (2), 239-255.

Van Loon, A.F. and Van Lanen, H. a. J., 2013. Making the distinction between water scarcity and drought using an observation-modeling framework. Water Resources Research, 49 (3), 1483-1502.

van der Voorn, T., Pahl-Wostl, C., and Quist, J., 2012. Combining backcasting and adaptive management for climate adaptation in coastal regions: A methodology and a South African case study. Futures, 44 (4), 346-364.

Walker, G., 2014. Water Scarcity in England and Wales as a Failure of (meta)Governance. Water Alternatives, 7 (2), 388-413.

Water UK, 2016. Water resources long term planning 2015-2065. London, Technical Report. Wilkinson, A. and Eidinow, E., 2008. Evolving practices in environmental scenarios: a new scenario typology. Environmental Research Letters, 3 (4), 045017. 
Figure 1. Matrix of influencing factors "Policy"

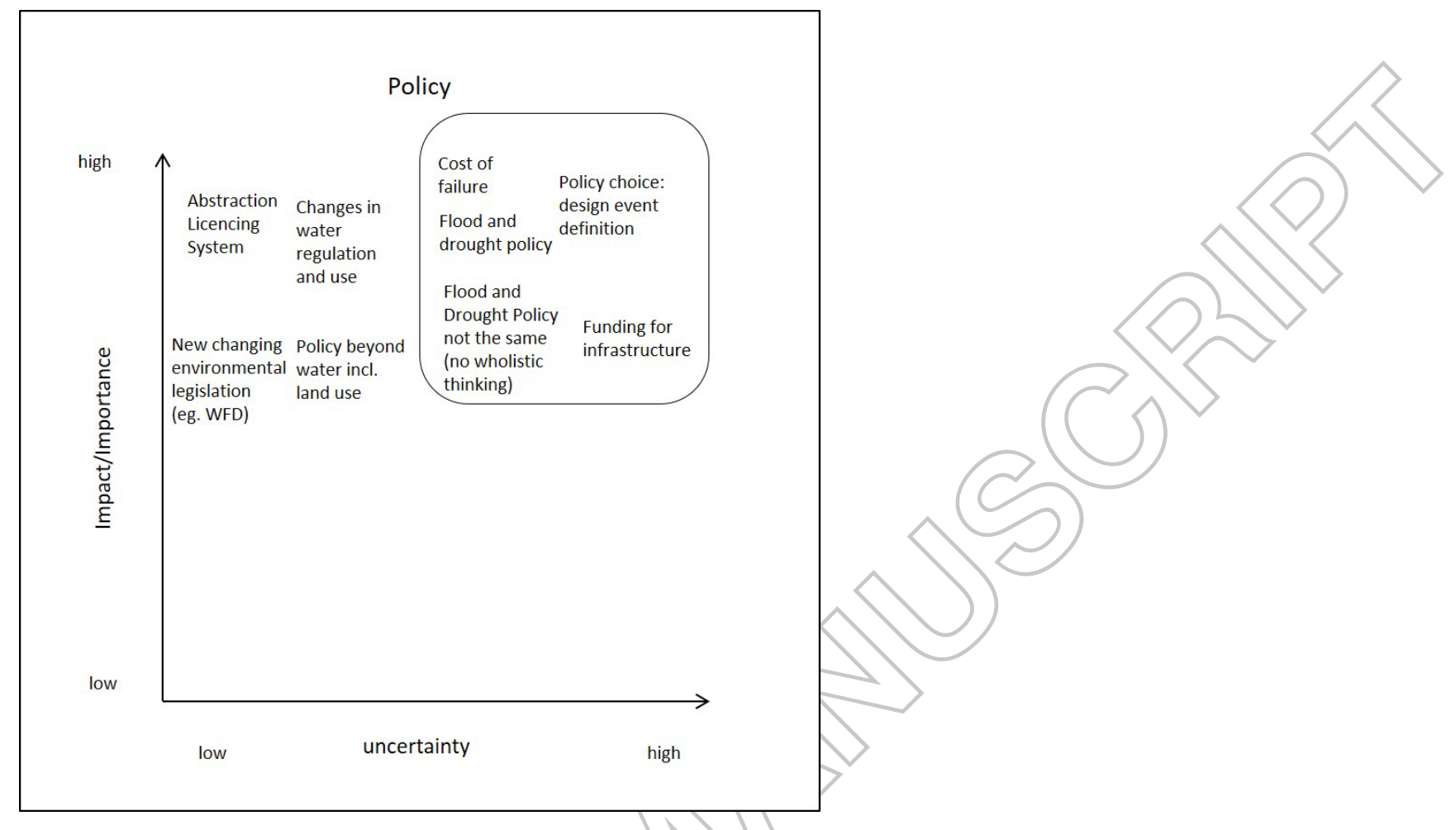


Figure 2. Scenarios "Resilient Drought and Water Scarcity Management in England and Wales by 2065”

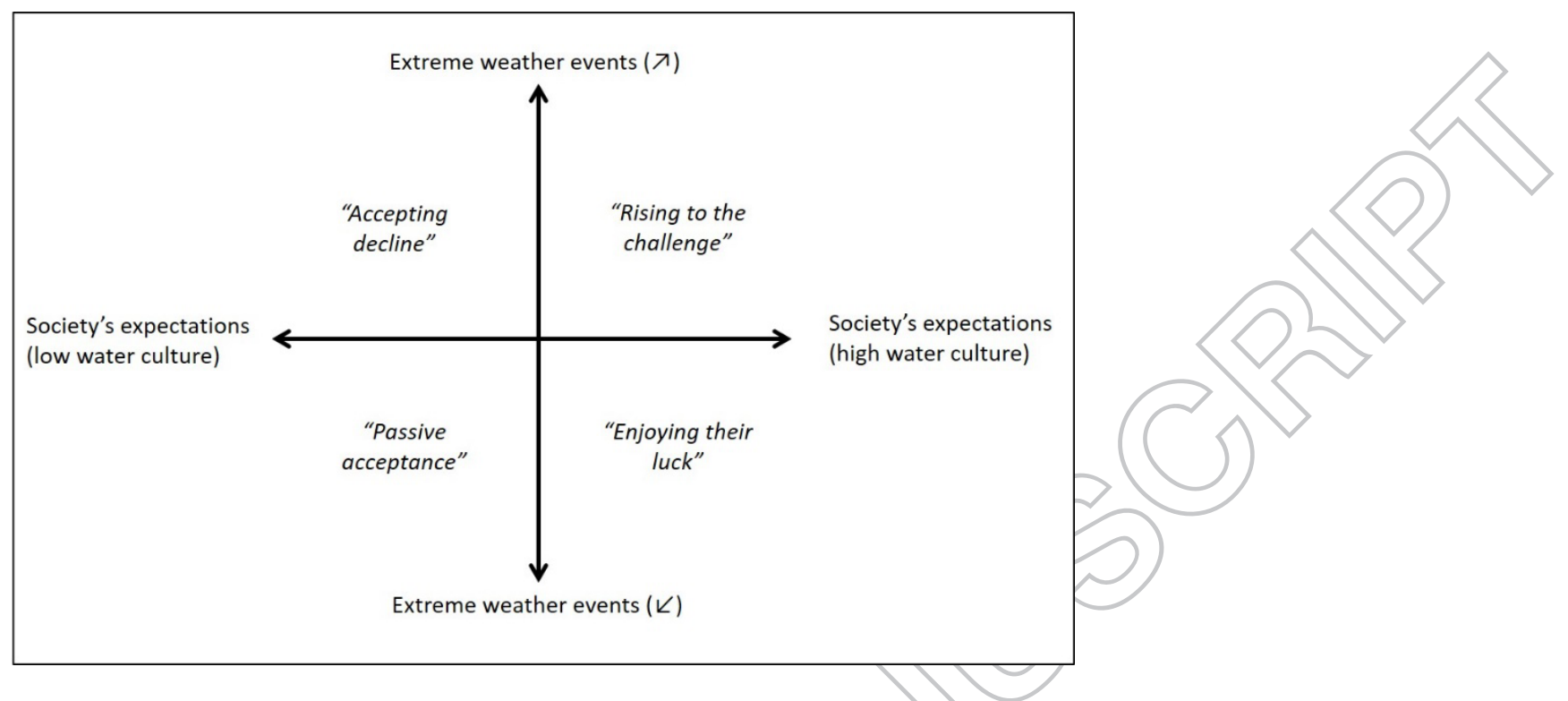


Table 1. Problem Frame

\begin{tabular}{|l|l|}
\hline Dimension & Institution \\
\hline temporal & 2065 \\
\hline spatial & England \& Wales \\
\hline topical & Resilient Drought and Water Scarcity Management \\
\hline
\end{tabular}


Table 2. List of all drivers and influencing factors identified as "highly uncertain" and of "high importance"

\begin{tabular}{|c|c|}
\hline \multirow[t]{4}{*}{ Policy } & Policy choice: Design event definition \\
\hline & Flood and drought policy \\
\hline & $\begin{array}{l}\text { Flood and drought policy not seen as the same cycle (no wholistic } \\
\text { thinking) }\end{array}$ \\
\hline & Cost of failure \\
\hline \multirow[t]{8}{*}{ Weather/Climate } & Extreme weather events \\
\hline & Extreme droughts \\
\hline & Rainfall Patterns \\
\hline & Climate change and weather variability \\
\hline & Climate change \\
\hline & Knowledge of water resources status (incl. climate change) \\
\hline & Climate change - influence on water availability \\
\hline & Population and climate change (less rainfall, more hot days) \\
\hline \multirow[t]{10}{*}{ Economic Development } & Industry development \\
\hline & Have we cracked electricity storage? \\
\hline & Size and shape of economy \\
\hline & Changes to the economic impact of drought (resilience) \\
\hline & Intergenerational funding (who pays for tomorrow) \\
\hline & Abstraction increases (private and agriculture) \\
\hline & Technology \\
\hline & Can we share resources (institutions, markets, co-operation) \\
\hline & Willingness to share (geographical) \\
\hline & Power generation mix (dependency on water) \\
\hline \multirow[t]{8}{*}{ Behaviour } & Society's expectations \\
\hline & Level of environmental protection by society \\
\hline & Water use culture \\
\hline & Consumption per person change \\
\hline & Water use behaviour and value \\
\hline & Customer inertia to change ("water is free" \& "it rains all the time") \\
\hline & Billing and volumetric (S.E.P.) \\
\hline & Increasing customer demands (technology, urbanisation) \\
\hline \multirow{4}{*}{ Environmental Needs } & Unsustainable environment \\
\hline & Land use change (ecological) \\
\hline & Demand for environmental quality by 2065 \\
\hline & Changing needs of the environment for other water users \\
\hline \multirow[t]{2}{*}{ Intervention } & Cost of capital for infrastructure \\
\hline & Innovation and technology \\
\hline
\end{tabular}


Table 3. List of drivers and their importance

\begin{tabular}{|l|c|}
\hline Driver & Point based assessment \\
\hline Society's expectations / Water use culture & 9 \\
\hline Extreme weather events (droughts) & 8 \\
\hline Flood and drought policy & 6 \\
\hline Willingness to share water & 5 \\
\hline Cost of failure & 5 \\
\hline Policy choice: design event definition & 4 \\
\hline Unsustainable environment & 3 \\
\hline Billing and volumetric & 2 \\
\hline Demand for environmental quality & 2 \\
\hline
\end{tabular}


Table 4. Development of critical drivers in each scenario

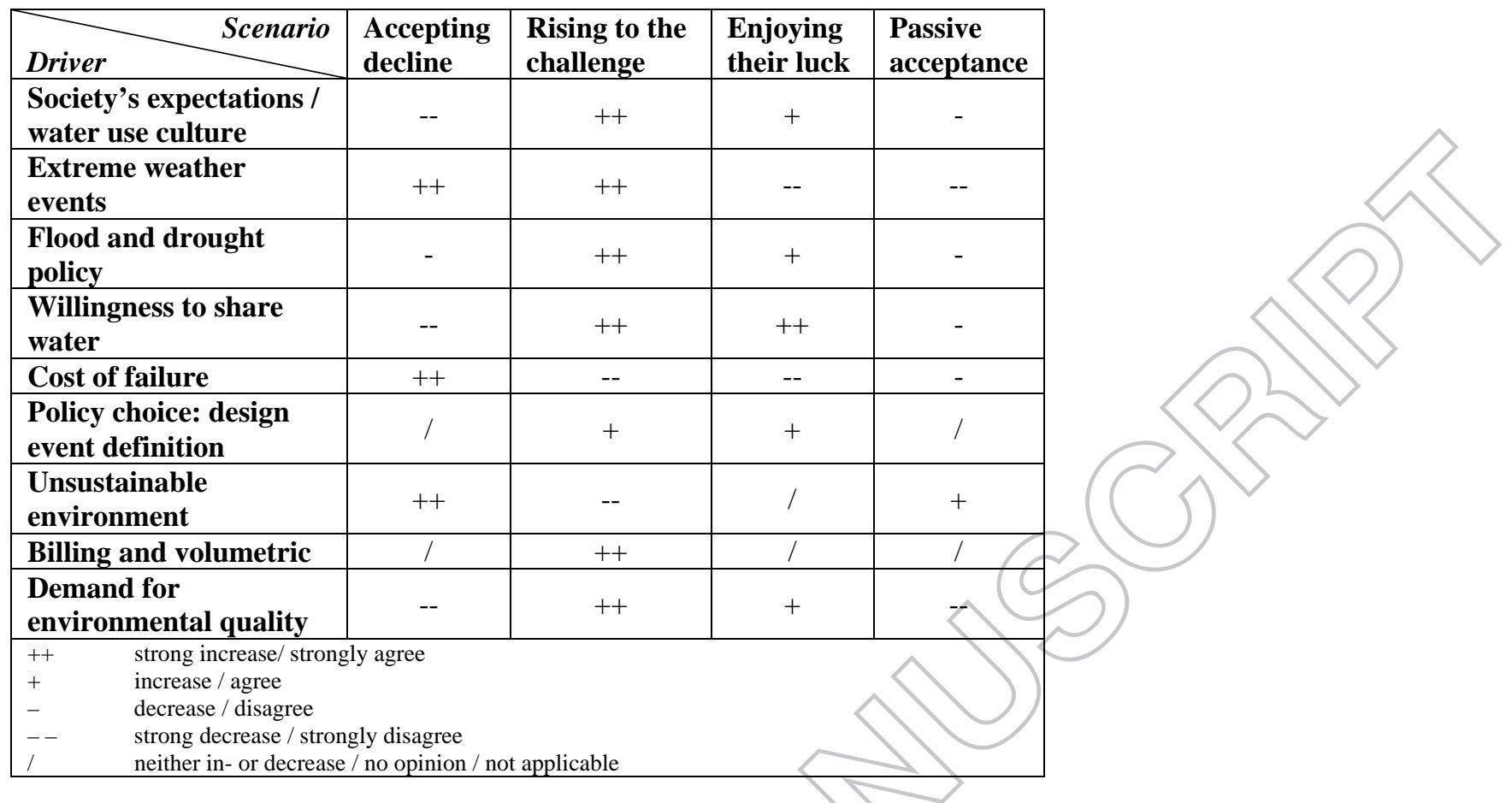

